\title{
Heidegger e a Sustentabilidade
}

\section{Heidegger and Sustainability}

Prof. Dr.Edgar Lyra

PUC - Rio

Este texto realiza dois movimentos. O primeiro concerne àquilo que Heidegger chamaria de solo ôntico do mundo contemporâneo, mais especificamente, ao estado de coisas que hoje engendra o chamado "debate ambiental". O ponto de chegada deste primeiro movimento é a chamada de atenção para a atual inexistência de uma discussão pública mais substancial sobre o homem, como ente cujas necessidades devem ser prioritária e imperativamente satisfeitas, agora de forma sustentável. O segundo movimento é o de tecer fios capazes de inserir, tão organicamente quanto possível, os textos e questões heideggerianas neste debate. Não se pretende com isso reivindicar para Heidegger nenhuma verdade definitiva sobre o homem e seus direitos em relação ao cosmos, mas, sobretudo, alertar para a importância daquilo que jaz impensado sob o calor das atuais urgências.

PALAVRAS-CHAVE

Heidegger; Sustentabilidade; Antropologia Filosófica; Debate Ambiental

This paper performs two movements. The first concerns what Heidegger would call ontical ground of the contemporary world, more specifically, the state of things that today engenders the so called "environmental debate." The end point of this first move is to call attention to the current lack of a more substantive public discussion about the man, as a being whose needs must be prioritized and imperatively satisfied, now in a sustainable way. The second movement involves weaving wires capable of inserting, as organically as possible, Heideggerian texts and issues in this debate. This means not to claim for Heidegger the definitive truth about man and his rights in relation to the cosmos, but especially alert to the importance of what lies thoughtless in the heat of the current urgencies.

\section{KEY-WORDS $\begin{aligned} & \text { Heidegger; Sustainability; Philosophical Anthropology; } \\ & \text { Environmental Debate }\end{aligned}$}


Sustentabilidade é hoje um termo amplamente conhecido. Sustainability gera no Google 105 milhões de resultados; a chave em português 18,9 milhões. ${ }^{1}$ Links associados ao termo, ou ao seu correlato, desenvolvimento sustentável, são encontrados sem dificuldade nas homepages de boa parte das grandes empresas contemporâneas. Intimamente ligado à institucionalização do debate ambiental, o termo trifurcou-se em "sustentabilidades" interligadas: ambiental, social e econômica. A busca por sustentabilidade foi, em suma, carro-chefe da Rio +20 , onde e quando se esperava, com maior ou menor otimismo, que passos sustentáveis fossem dados pela chamada "governança global". O resultado, como se sabe, ficou pragmaticamente aquém das expectativas.

A noção de sustentabilidade foi institucionalmente definida e acolhida pela chamada Comissão Mundial sobre Meio Ambiente e Desenvolvimento no relatório Nosso Futuro Comum, publicado em 20 de março de 1987, ou seja, há pouco mais de 25 anos. Sustentável, desde então, é o desenvolvimento "que atende às necessidades do presente sem comprometer a possibilidade das gerações futuras atenderem às suas próprias necessidades". "Atendimento de necessidades" e "necessidade de desenvolvimento" caminham, portanto, lado a lado na definição. Tudo isso em benefício das gerações presentes e futuras; bem entendido, gerações de seres humanos; bem entendido, gerações presentes e futuras: as passadas não são citadas.

Ora, mesmo que as palavras "desenvolvimento" e "necessidade" presentes na definição envolvam pressupostos antropológicos, biológicos, psicológicos, éticos, políticos, econômicos, lógicos e ontológicos, pressupostos de todo modo muito complexos em seu enredamento e priorização, o que hoje efetivamente se discute - e mesmo em função das urgências e das ameaças de irreversibilidades, de non returning points - são estratégias de desenvolvimento capazes de tornar perene o atendimento das necessidades humanas presentes e futuras. Há, inclusive, quem conjecture que o formidável poder de aglutinação política do termo sustentabilidade deriva justamente da sua vagueza, melhor dizendo, da variedade de interesses e sentimentos que podem por isso com ele se identificar. ${ }^{3}$ Trata-se, e isso é afinal o que importa, da satisfação de necessidades humanas.

1 Todos os links fornecidos tiveram acessos em 22/12/2012.

2CMMAD, 1991, p. 9.

3 NOBRE e AMAZONAS, 2002 
Esse guarda-chuva conceitual não é, todavia, tão frondoso ou ecumênico como publicamente tem parecido. Até porque a definição Brundtland deu rosto a um conjunto de reações às prescrições de "crescimento zero" surgidas no início dos anos 1970, presentes, por exemplo, em textos como The Population Bomb (1968), escrito por Paul Ehrlich, e Limits to Growth (1972), organizado por Donella Meadows a partir do Clube de Roma ${ }^{4}$ Fato relevante é que já em junho de 1972 sobreveio a Conferência de Estocolmo, e com ela a declaração sobre o "ambiente humano", que afirmava ter o homem "direitos fundamentais" e carecer constantemente de somar experiências "para continuar descobrindo, inventando, criando, progredindo". Dizia ainda o texto que "hoje em dia, a capacidade do homem de transformar o que o cerca, utilizada com discernimento, pode levar a todos os povos os benefícios do desenvolvimento e oferecer-lhes a oportunidade de enobrecer sua existência"s. Ato contínuo, isto é, em dezembro do mesmo ano, em prol dos "benefícios do desenvolvimento" ou, o que dá no mesmo, contra quaisquer possíveis tendências antidesenvolvimentistas, criava-se o PNUMA (Programa das Nações Unidas para o Meio Ambiente), com o qual se institucionalizou de vez o debate ambiental internacional; e, com ele, a busca de uma nova noção de desenvolvimento compatível com a finitude dos recursos naturais, com os ciclos de regeneração do planeta e, mais importante, com a viabilização da possibilidade de continuar perpetuamente satisfazendo as necessidades humanas, geração após geração.

Feito esse excurso ao contexto Roma-Estocolmo, voltemos a 1983, quando foi instituída pela ONU a já aludida Comissão Mundial sobre Meio Ambiente e Desenvolvimento, presidida pela primeira ministra norueguesa Gro Harlem Brundtland (1939 - ) e, por isso, mais conhecida como Comissão Brundtland. Essa comissão tomou a seu encargo "propor uma agenda global para a mudança", mais especificamente, "estratégias ambientais de longo prazo para obter um desenvolvimento sustentável por volta do ano 2000, e daí em diante" ${ }^{\text {. A }}$ ideia de desenvolvimento precisava rever-se, em especial para assegurar que não inviabilizaria a si mesma, tornando-se insustentável. Já então, pelas prescrições do relatório, deveriam caminhar juntas as três citadas sustentabilidades: ambiental, social e econômica.

O amálgama de desenvolvimento e perene atendimento de necessidades

4Acrescente-se os títulos Silent Spring (1962), de Rachel Carson e The Tragedy of the Commons (1968), de Garrett Hardin.

5 ONU, 1972, p. 1.

6 CMMAD, 1991, p. XI. 
patenteado pela Comissão Brundtland abriu caminho, por sua vez, para desdobramentos importantes. Colocou em epígrafe a assimetria entre países ricos e países pobres, isto é, o descompasso entre as diversas necessidades a serem satisfeitas e os diferentes modelos de desenvolvimento capazes de satisfazê-las. Definiu-se por esses caminhos, na Convenção-Quadro da Rio $92^{7}$, um novo mandamento, o das "responsabilidades comuns porém diferenciadas", que acabou por inspirar os famosos "Anexos" do Protocolo de Quioto ${ }^{8}$. O "direito ao desenvolvimento" ganhou, previsivelmente, a simpatia dos países pobres e dos países "em desenvolvimento", atravessando, por exemplo, a íntegra do muito aplaudido discurso do Presidente Lula em Copenhagen (2009). Chegamos à Rio +20 , enfim, com a certeza de que a questão ambiental, para encontrar solução, não poderia ser pensada senão como estratégia de desenvolvimento global integrado e atento às desigualdades socioeconômicas. Resta saber, do ponto de vista do "futuro comum que queremos", 9 o que, exatamente, decorre de uma opinião pública que consente, por um lado, que todos os humanos têm direito a satisfazer suas necessidades e que precisam para isso desenvolver-se; e, por outro lado, que já intui que a satisfação conjunta dessas necessidades tem de fazer-se em ritmo ou de forma que não venha a exaurir o planeta e assim inviabilizar-se.

É sempre tentador, neste ponto, restringir a discussão à tentativa de circunscrição de um conjunto de necessidades básicas a serem priorizadas e legitimamente atendidas, mas não parece ser sequer isto o que até agora foi clara ou pontualmente posto em questão. Tem-se por matemática certeza, por exemplo, a impossibilidade de franquear a todos os seres humanos o padrão de vida médio dos norte-americanos e dos europeus, sobretudo se levarmos em conta os países "em desenvolvimento" mais populosos, como a China e a Índia, progressivamente mais fascinados pelos padrões de consumo ocidentais. O quadro é deveras estranho. Aqui e ali, o flerte com a possibilidade de maximizar a eficiência tecnológica para que todos, habitantes do Mali, da Índia e do Rio de Janeiro possam afinal deslocar-se tão rápida e facilmente quanto desejem, aquecer-se e refrescar-se plena e prontamente conforme a necessidade ou o prazer. Essa crença numa tecnologia capaz de tornar mais econômicas essas "liberdades" convive, por sua vez - e não sem conflitos -, com o diagnóstico de que a migração para a sustentabilidade passaria, necessariamente, por uma mudança rumo a uma maior frugalidade, especialmente da parte dos povos e culturas que exportam seus modos de vida.

7ONU, 1992

8 ONU, 1997

9 Título do relatório final oficial da Rio +20 . 
Talvez possamos compreender, por esse mesmo caminho, por que tanta disputa em torno da real magnitude e velocidade das mudanças climáticas, ou por que a hipertrofia da questão do aquecimento global relativamente a outros desequilíbrios visivelmente em curso. Independentemente da certeza científica de que possam efetivamente chegar a revestirem-se as projeções mais alarmantes, há fortes indícios para crer que apenas a pressão de uma catástrofe ambiental palpável, num horizonte temporal mensurável, possa ter real poder de persuasão sobre os hábitos consumistas. E justo porque essa mudança de hábitos rumo a uma maior frugalidade se choca fortemente com os interesses mais obstinadamente desenvolvimentistas - que via de regra financiam a pesquisa científica -, volta e meia levantam-se vozes negando ou relativizando as projeções "oficiais" relativas às mudanças climáticas. Numa avenida de mão dupla, cientistas acusam cientistas de, em nome de interesses estranhos, manipularem dados e pesquisas.

\section{- II -}

Vale a pena, para dar conta das querelas, desconfortos e impasses acima descritos, mapear as posições atualmente mais visíveis diante da questão ambiental. Com isso se completará o primeiro movimento deste texto. Seguimos o sociólogo Bill Devall, da Humboldt State University, na divisão tripartite que faz em seu texto The Deep Ecology Movement. ${ }^{10}$

A primeira posição responde pelo nome de "paradigma dominante", quase um pleonasmo. Essa vertente apega-se à

crença de que 'crescimento econômico', medido pelo Produto Interno Bruto (PIB), é a medida do progresso, de que o principal objetivo dos governos dos estados-nação, após a defesa nacional, deve ser o de criar condições que permitam aumentar a produção de commodities e satisfazer as necessidades materiais dos cidadãos, enfim, a crença de que 'a tecnologia pode resolver nossos problemas'. A natureza, neste paradigma, é apenas uma fonte de recursos que deve ser 'desenvolvida' para satisfazer o crescente número de humanos, como também, a crescente demanda dos humanos (DEVALL, 2008, p. 472).

10DEVALL, 2008. Publicado originalmente em Natural Resources Journal, New Mexico, 20/2, 1980, p. 219-313. As traduções das citações desse texto são todas minhas. 
Para essa primeira perspectiva, portanto - resta saber se ainda dominante - o atual modelo de desenvolvimento é perfeitamente sustentável e abrirá inventivamente seus caminhos pela via da ciência e da tecnologia. Bom exemplo dessa convicção pode ser encontrado no discurso do engenheiro Eric Drexler (1955 - ), por alguns chamado de pai da nanotecnologia por ter defendido no MIT a primeira tese doutoral sobre o assunto. Drexler imagina, dependendo apenas de vontade político-econômica, ser possível resolver nanotecnologicamente os problemas socioambientais mais graves, dessalinizando água, sequestrando carbono e multiplicando exponencialmente a fertilidade dos solos, tudo isso de forma economicamente viável. $\mathrm{O}$ grande problema, segundo essa visão, seria justo o atraso do desenvolvimento técnico-científico por interesses político-econômicos, não raro atacados pela praga da corrupção. Não menos curioso é o fato de o autor falar, sem reservas, também do grande impulso ao desenvolvimento armamentista que essas novas tecnologias darão, explicando que, assim como se deu na Revolução Industrial, quem a elas não aderir ficará relegado a posições de subserviência e perda de autonomia. ${ }^{11}$

A segunda e central posição abrange as correntes reformistas, que hoje englobam a maior parte dos pleitos por um mundo sustentável, inclusive aquele institucionalizado pela ONU. Embora diversos e matizados, esses discursos têm em comum a ideia de que o atual modelo de desenvolvimento precisa e pode reformar-se por dentro, sem rupturas, sendo para isso necessário redefinir a noção de desenvolvimento de modo a nela incluir as muitas externalidades das quais, até hoje, o main stream teria gratuitamente se alimentado. A matriz ética subjacente a esses reformismos parece ser a utilitarista, num sentido próximo ao proposto por Jeremy Bentham (1748-1832) na passagem do século XVIII para o XIX. Seria o caso, em suma, de incluir no cálculo benthaniano a totalidade das variáveis que atualmente nos concernem e que devem proporcionar aos homens, de hoje e do futuro, a vida mais satisfatória possível - nos termos do autor, $a$ maior felicidade possível para o maior número possível de pessoas. Conquanto o difícil problema de efetivação de tal cálculo persista, e mesmo se complexifique no atual momento civilizacional, o fato é que existem impressionantes esforços de quantificação das variáveis envolvidas, esforços que vão dos mercados de carbono e da precificação das externalidades florestais, à tentativa butanesa, com adeptos hoje em alguns países da Europa e das Américas, de definir bases empíricas para hierarquizar níveis de desenvolvimento não mais em termos de PIB, mas de FIB - Felicidade Interna Bruta (ou GNH - Gross National Happiness). ${ }^{12}$

11 DREXLER, 2009.

12 Cf. http://www.felicidadeinternabruta.org.br/ 
É inclusive difícil estabelecer limite e delineamento claro para o referido reformismo. Observou-se na Rio +20 , por exemplo, uma forte contestação ao relatório oficial do evento por parte da chamada Cúpula dos Povos. Em sua Declaração Final, de subtítulo Cúpula dos Povos na Rio +20 por justiça social e ambiental, em defesa dos bens comuns, contra a mercantilização da vida ${ }^{13}$, percebe-se sobretudo uma inversão de dois dos termos do tripé Brundtland: as questões sociais buscam impor-se às econômicas. Embora se fale aqui e ali de "direitos da natureza" e de "solidariedade e respeito às cosmovisões e crenças dos diferentes povos", depreende-se dos 16 "eixos de luta" enumerados no documento que a preocupação está fortemente concentrada na busca de uma melhor distribuição da riqueza, e na denúncia da "economia verde" como fachada produzida no seio da "atual fase financeira do capitalismo" para manter os privilégios deste último. Os ativistas da Cúpula dos Povos, em outras palavras, identificam o debate institucional ambiental com o "paradigma dominante", acusando seus protocolos e ações de tecnicistas e capitalistas. Lê-se logo no primeiro parágrafo do documento que se trata de "frear a nova fase de recomposição do capitalismo e de construir, através de nossas lutas, novos paradigmas de sociedade".

Bill Devall identifica ainda uma terceira posição, em tese diametralmente oposta ao "paradigma dominante", que compreende as correntes reunidas sob o nome de deep ecology. O autor diz preferir esse termo a outros como "ecologia radical", justamente para evitar sua identificação com um sentido mais estrito, necessariamente ativista, de forçar mudanças de forma não raro bizarra. $\mathrm{O}$ termo deep ecology foi cunhado em 1973 pelo filósofo norueguês Arne Naess (19122009) e, em seu aspecto mais geral, trabalha com a ideia de que não há reforma possível do atual modelo desenvolvimentista, ou seja, que se faz necessária uma visão de mundo radicalmente nova, na reformulação de Devall, "uma nova metafísica cósmico-ecológica, capaz de sublinhar a identidade do homem com a natureza não humana"14. Seria, diz-se, uma questão de tempo para que os reformistas ou "ecologistas superficiais", como os profundos os rotulam, compreendessem a vacuidade, ou mesmo as contradições, alojadas em seus projetos.

Mas, são também verificavelmente diversificadas essas posturas mais radicais, tanto em suas fontes de inspiração - que vão do modo de vida de povos primitivos aos orientalismos, misticismos e à contracultura - quanto na materialização dos seus discursos e ações. Filosoficamente falando, essas posições tendem a afastar-se dos chamados "antropocentrismos" e a clamar por uma revisão da relação do homem com a Natureza, ou de sua posição no Cosmos, sobretudo buscando resgatar uma dignidade intrínseca para o não humano, fun-

13 CÚPULA DOS POVOS, 2012.

14DEVALL, 2008, p. 476. 
dada em algo diferente da mera capacidade utilitária de servir-nos.

Torna-se imperativo, nesses casos, discutir e tornar compreensíveis as bases dessa dignidade do não humano, até porque, sem esse esclarecimento, é muito provável que o sentimento de ridículo referido por Roderick Nash (1939 - ), ${ }^{15}$ professor de Estudos em História e Meio Ambiente na Universidade de Santa Bárbara, torne impossível qualquer diálogo e consequente deslocamento em relação às perspectivas mais utilitárias e antropocêntricas. Diz Nash no artigo Do the Rocks have rights? (1977):

As pedras têm direitos? Se vier o tempo em que para qualquer grupo considerável de americanos tal questão não mais seja ridícula, estaremos à beira de uma mudança na estrutura de valores que poderá viabilizar medidas para lidar com a crescente crise ecológica. Espera-se que haja tempo suficiente (apud DEVALL, 2008, p. 476). ${ }^{16}$

Merece ser transcrita, para finalizar este mapeamento e para posterior comentário, também uma citação extraída do livro Touch the Earth (1971), na verdade uma fala do Oglala Sioux Luther Standing Bear:

Não pensamos nas grandes planícies abertas, nas montanhas rochosas e nos rios sinuosos que vão se misturando uns aos outros como "selvagens". Só para o homem branco a natureza era "selvageria" e só para ele estava a terra "infestada" de animais "selvagens" e gente "selvagem". Para nós a terra era mansa. A terra era generosa e estávamos rodeados de bênçãos do Grande Mistério. A terra não era selvagem até que os homens cabeludos vieram do leste e com furor brutal amontoaram injustiças sobre nós e sobre as famílias que amávamos. Foi quando os próprios animais começaram a fugir ante essa aproximação que "oeste selvagem" começou (apud DEVALL, 2008, p. 474). ${ }^{17}$

15 Cf. NASH, R. Wilderness and the American Mind (1967) e The Rights of Nature (1989). 16 O texto foi originalmente publicado em The CenterMagazine, Santa Barbara, 10, 1977:2. $17 \mathrm{O}$ texto foi originalmente publicado em McLUHAN, T.C. Touch the Earth: a self-portrait of indian existence. New York: Outerbridge \& Diesntfrey, 1971. 


\section{- III -}

Martin Heidegger (1889-1976) é, volta e meia, citado entre os pensadores ambientais, sendo incluído por Joy Palmer em sua coletânea Fifty Key Thinkers on the Environment (2006) ao lado, entre outros, de Buda, São Francisco de Assis, Charles Darwin, Arne Naess, Paul Ehrlich, Gro Brundtland, Chico Mendes e Vandana Shiva. Aparece por vezes definido como um dos inspiradores da deep ecology, como acontece no texto de Bill Devall há pouco mencionado. Mas, especialmente este último alinhamento não se dá sem contestações, a mais importante delas, para os propósitos aqui em pauta, ligada à ideia de que o "homem heideggeriano" continuaria a ocupar posição central entre os demais entes, mais do que isso, que Heidegger estaria preocupado, primeira e principalmente, com o homem ocidental, europeu, alemão, mais pontualmente ainda com pensadores e poetas, fazendo girar em torno destes, em círculos concêntricos, todos os outros entes. Há decerto outras contestações, desde puras rejeições ético-políticas ligadas à alegada impossibilidade de esquecer seu compromisso da década de 1930 com "a verdade e a grandeza internas do Nacional Socialismo" até temores daí derivados, de que seu pensamento pudesse dar ensejo à "ascensão de elementos totalitários ou ecofacistas no pensamento ecológico radical" (PALMER, 2006, p. 195). Mas, reconhecendo a originalidade das teses heideggerianas e, imaginando que sua simples rejeição apenas contribuiria para uma anacrônica simplificação do debate capitaneado pela deep ecology, nos ocuparemos aqui preferencialmente da procedência das questões por ele postas em seu apelo antropológico-ambiental. Tratam-se, bem entendido, de questões cruciais, presentes, por algum desconhecido motivo, na obra de Heidegger.

Contam-se, de fato, vozes muito variadas na crítica ao antropocentrismo, desde as que pugnam por uma necessária diferenciação entre antropocentrismo e humanismo, tentando salvar este último, até as que vêm no homem, mesmo quando solidário aos seus semelhantes, uma espécie de câncer ou vírus que infesta o tecido cósmico, espécie, afinal, que melhor seria jamais ter existido. No seio de tamanho dissenso encontra-se considerável atrofia da interrogação sobre o lugar essencial do homem em meio aos demais entes, atrofia que desemboca numa generalizada falta de clareza a respeito do que seria afinal uma "postura não antropocêntrica", "holística", "cósmica", ou que nome venha a ter. Em suma, se da parte do main stream desenvolvimentista - e mesmo dos que creem na possibilidade de sua reforma - a questão do homem, dos seus direitos e necessidades sequer pode ser seriamente posta, no âmbito das ecologias radicais o anseio difuso e urgente por um mundo não antropocêntrico, que 
acompanha a recusa do atual estado de coisas, acaba tendo efeito semelhante.

Por tudo o que foi dito e, mais uma vez, sem reivindicar para Heidegger a desejável, correta ou definitiva concepção da natureza humana, o trabalho a ser feito é o de, através de sua obra, convidar a enfrentar algumas atrofias importantes no atual debate ambiental. O escopo deste artigo impõe, todavia, que ele se se restrinja à sinalização de campos interrogativos passíveis de potencialização no discurso da ecologia profunda, sinalização que, decerto, careceria de tratamento "retórico" para ganhar âmbitos mais amplos que o dos arraiais filosóficos, quiçá heideggerianos. O presente conjunto de indicações se aterá, em suma, a duas linhas de questionamento progressivamente entrelaçadas na obra do pensador alemão: a) a singular forma de Heidegger colocar a questão do ser do homem e b) a leitura do atual momento civilizacional viabilizada por suas reflexões sobre a técnica moderna.

\section{- IV -}

Desloquemo-nos para a obra de Heidegger. É de fato difícil negar que o Dasein (ser-aí) por ele nomeado (como uma espécie de correlato histórico-existencial do homem) seja um ente especial. São reivindicados, logo na introdução de Ser e Tempo (1927), privilégios "ôntico e ontológico" para este ente, privilégios consonantes com o fato de ser justamente a partir de uma analítica do Dasein que Heidegger buscou abrir caminho para sua ontologia fundamental. Se a intenção for, portanto, univocamente a de salvar o autor do rótulo de "antropocentrista", o caminho mais curto talvez seja o de recorrer à viravolta (Kehre) na sua obra, por ele mesmo nomeada em Sobre o Humanismo, em 1947. Heidegger então critica o primado do homem em relação ao Ser presente em seu projeto de ontologia fundamental, afastando-se inclusive, explicitamente, de todo humanismo, por ele entendido como irremediavelmente trespassado por um tom metafísico, a saber, pela redução do Ser ao status de ente fundamental capaz de atender às necessidades humanas de fundamentação das suas Paideias.

Mas, não é à toa que se discute a relevância, a natureza e a extensão da referida viravolta. Entende-se que Heidegger tenha assim "empobrecido o homem", fazendo seu pensamento descer de píncaros por ele mesmo ditos "metafísicos" para a "pobreza da sua essência provisória". ${ }^{18}$ Esse empobrecimento, contudo, não significa por si só nenhuma descaracterização do Dasein como

18 HEIDEGGER, 1956, p. 47 . [...] vorläufige Wesens no original, tradução minha. 
lugar da pergunta pelo Ser - seu próprio ser, dos demais entes e da relação entre ambos. Vale assim a pena, a bem da aludida irrigação do debate ambiental, e não apenas de uma "salvação de Heidegger", encontrar formas de discutir mais ilustrativamente o que significa dizer que, a partir da viravolta, é o Ser que vem em direção ao homem, e não o inverso.

Ser, para Heidegger - não é demais abrir parêntese para frisar -, é, sobretudo, "algo" que, no enigma da sua vigência multifária, dá a pensar. Não se trata, por isso, prima facie de nenhuma voz grave, emissora de ditames ou carente de subserviência.

Fato é que com o termo Dasein Heidegger nomeia o ente no qual se dá a compreensão, ainda que prévia, incompleta, obstruida, implícita ou explícita, de algo há muito nomeado pela palavra "Ser". "Somos", enfim, todos nós, "Daseins", partícipes de um mesmo destino, herdeiros de um conjunto entrelaçado de tradições e falantes de línguas nas quais se conjuga o verbo ser: em outras palavras, entes potencialmente abertos para a pergunta sobre o ser dos variadíssimos outros entes em sua inextricável unidade.

Animais e plantas, ainda que se possa discutir a presença de autoconsciência em alguns deles, até onde se sabe não perguntaram e não perguntam pelas partículas ou pelo plasma constituinte do Universo, também não pelo Lógos que as conforma ou pela energia que as move, tampouco pelo fim a que tudo tende ou deve tender. Não colocam em questão, em suma, o ser das coisas que os cercam, não havendo registro de nenhum Poema de Parmênides entre eles, tampouco de testes nucleares ou projetos genéticos de superação da animalidade. Muito provavelmente por isso Heidegger se volta primeiro para o Dasein. Por razões a buscar, seu modo de ser impôs-se ao dos animais, domesticando-os, extinguindo-os, lutando por sua preservação e dignificação, ou triturando-os vivos em inocentes granjas ao redor do mundo. E, ainda que em seu Os Conceitos Fundamentais da Metafisica: mundo, finitude, solidão (1929), concebido dois anos depois de Ser e Tempo, se discuta a possível relação de entes não humanos com algo como "mundos", o que parece então estar mais pontualmente em questão é um melhor entendimento daquilo que nós chamamos de mundo e do sentido em que somos formadores de mundo.

É razoável admitir, por mais místicos que alguns individualmente se pretendam, que estamos coletivamente presos à nossa forma humana de compreensão dos entes em geral, se não pela singularidade dos nossos sentidos e do nosso intelecto, pelo menos pela memória dos nossos feitos, pela nossa linguagem e pelos instrumentos de que nos servimos. É possível em seguida sugerir que, 
somente emulados por aquilo que mais singularmente em nós "acontece", ou pode acontecer $^{19}$ - reconhecendo nisso algo de extraordinário -, seremos de fato capazes de nos abrir para os mistérios da formação de mundo em geral e, por aí, para a interrogação sobre outros mundos, mesmo "mais pobres" que o nosso. Por problemática que seja essa sugestão, ao aceitar discuti-la estaríamos já em vias de estranhar (com sorte, publicamente) a própria ideia de mundo e, conjuntamente, aquilo que, não sendo da ordem do mundo, nutre os vários entes e lhes permite serem o que são, não importa se mais ou menos ricos de "mundo" - sem falar das noções mesmas de pobreza e riqueza, de todo latentes não só no debate ambiental, mais em todo o projeto ocidental. Vale lembrar que Heidegger muitas vezes nos alertou para o perigo extremo da "indigência da falta de indigência" - ou de necessidade - e que escreveu, por exemplo, em 1945 um opúsculo, Die Armut, dedicado ao tema da pobreza. ${ }^{20}$ Não se perca de vista, enfim, a questão das necessidades humanas que subjaz ao conceito de sustentabilidade.

Note-se ainda que, mesmo do ponto de vista de uma ética mais restrita, que envolva apenas os humanos, surge o problema da comparação do Dasein de Heidegger com os "Daseins" descolados da tradição eurocêntrica, como o de certos povos aborígenes ou bosquímanos, o povo de Luther Standing Bear, por exemplo. Mas, justamente a sua extinção, aculturação ou confinamento parece colocar com redobrada razão a necessidade de reabrir a questão do modo como o Dasein eurocêntrico compreende e tem historicamente compreendido o Ser em geral. Não é demais insistir, foi essa a forma que se tornou dominante e globalizou o mundo. Seria enfim estranho supor que esse Dasein pudesse realmente se interessar pelo modo de formar mundos de alteridades como as referidas, sem esvaziar-se - ou empobrecer-se - a ponto de estranhar o seu próprio existir.

É decerto sempre possível alegar que Heidegger estivesse mais preocupado com a qualidade do que acontece, ou pode acontecer, em pensadores e em poetas ainda capazes de pensamento meditativo, do que com o homem em geral - que dirá com animais, plantas e pedras. Menos restritivamente, pode-se insistir que seria o homem ocidental, mais diretamente imerso na hegemonia do pensamento calculativo (conforme formulado no opúsculo "Serenidade", de 1955) aquele por quem Heidegger principalmente temeu. E que, apenas visando a salvá-lo teria ele se interessado, por exemplo, por pistas vindas do Extremo Oriente. - Mas, não seria este mundo mesmo, ocidentalmente configurado,

19 Não simplesmente "conosco", mas em nós, entre nós, por meio de nós.

20 A mim cedido, por ocasião do Colóquio Heidegger de 2009, por Róbson Ramos dos Reis (UFSM). 
enrijecido pela hegemonia tremenda do enquadramento técnico, que precisaria primeiro ser salvo? - Não é esse o mundo que precisa irrigar-se, fertilizar-se em suas possibilidades de história futura, para poupar dos seus atuais planos-sem-fim quaisquer "outros mundos"?

\section{$-\mathrm{V}$ -}

A questão filosófica e antropológica até aqui esboçada mistura-se, bem se vê, com a questão da técnica e com as transformações do mundo a ela ligadas, transformação formidavelmente acelerada nos últimos séculos e que deságua no presente debate ambiental. A reflexão heideggeriana sobre a técnica, que vai se encorpando a partir do final dos anos 1930 e atinge seu apogeu em meados da década de 1950, pode ser assim de formidável valia, sobretudo por questionar alguns implícitos insidiosamente presentes no debate em pauta.

O mais importante desses implícitos é aquele que Heidegger chama de concepção antropológico-instrumental da técnica. ${ }^{21}$ Essa concepção, embora correta, tenderia em sua correção a velar o que há de mais essencial a pensar, e justo por apresentar-nos o homem como um ente autônomo a manusear objetos técnicos, senhor de uma técnica neutra que, vez por outra, por má fé ou incompetência, escapa-lhe ao controle - e que, portanto, precisa encontrar caminhos para o um desenvolvimento sustentável.

Heidegger opõe-se frontalmente a tal concepção da técnica alegando que, sem perceber - e tanto mais, quanto menos o percebe - o homem encontra-se ele próprio tecnicamente determinado em seu ser, isto é, perpetuamente convocado a "aperfeiçoar-se" e a dispor-se cada vez mais eficientemente em relação à totalidade de entes, incluídos aí os outros homens. Pensa a técnica moderna, assim, a contrapelo da tendência de enxergá-la como instrumento em progressiva sofisticação, ao qual poderíamos, fôssemos um pouco mais hábeis "politicamente", impor limites soberanos através de protocolos e leis, a fazer valer, inclusive, com auxílio de instrumentos de controle em progressiva sofisticação.

Uma réplica comum dos ambientalistas à elevação da técnica, por Heidegger, à condição de destino, é a de que isso nos imobilizaria justamente quando mais precisaríamos resistir e agir. Quem sabe pudéssemos trabalhar aí, mais amiúde, a noção heideggeriana de destino, distinguindo-a de "fatalidade" e vi-

21 HEIDEGGER, 2002. A conferência “A Questão da Técnica” foi proferida em 1953. 
rando as atenções para a real inércia ou poder de condicionamento do caudal técnico em que nos encontramos imersos? Mesmo que devêssemos prioritariamente discutir planos de ação, é razoável supor que nossas chances de êxito aumentassem com a aquisição de alguma lucidez a respeito das raízes e do atual grau do nosso condicionamento às formas técnicas de ser.

Há, com certeza, outras possíveis críticas às reflexões de Heidegger sobre a essência da técnica, no mais das vezes marcadas pelo diagnóstico de uma nostalgia do campo e de um preconceito do autor em relação ao progresso científico e tecnológico. Mas, todas elas podem, de forma mais ou menos instigante, ser remetidas à pergunta inicial pelo ser do homem e por sua desejável relação com o mundo pelo qual deveria responsabilizar-se. Passasse, enfim, a confiança no desenvolvimento técnico por uma séria e pública crítica a ponderações como as de Heidegger, teríamos um outro cenário. Quem sabe não pudessem inclusive os ecologistas mais profundos, num "caldo de cultura" assim espessado, encontrar linguagem para dizer (e serem levados a sério) o que efetivamente se perderia, caso lográssemos tornar sustentável algo como o "admirável mundo novo" imaginado por Aldous Huxley.

CARSON, R. Primavera Silenciosa, $2^{\mathrm{a}}$ edição brasileira. São Paulo: Melhoramentos, 1969.

CMMAD (COMISSÃO MUNDIAL SOBRE MEIO AMBIENTE E DESENVOLVIMENTO). Nosso Futuro Comum. Rio de Janeiro: Editora FGV, 1991.

CÚPULA DOS POVOS. Cúpula dos Povos por Justiça Social e Ambiental em Defesa dos Bens Comuns, contra a Mercantilização da Vida. Rio de Janeiro, 2012. In: http://cupuladospovos.org.br/2012/06/declaracao-finalda-cupula-dos-povos-na-rio20-2/

DEVALL, B. The Deep Ecology Movement. In: SCHARFF, R. andDUSEK, V. Philosophy of Technology: the technological condition. Malden: Blackwell, 2008.
DREXLER, E. Os Nanossistemas: possibilidades elimites para o planeta e para a sciedade. In: NEUTZLING, I. e

CARNEIRO DE ANDRADE P. F. Uma Sociedade Póshumana: possibilidades e limites das nanotecnologias. São Leopoldo: Ed. UNISINOS, 2009.

EHRLICH, P. The Population Bomb. New York: Buccaneer Books, 1968.

FIB: Felicidade Interna Bruta. In: http://www. felicidadeinternabruta.org.br/

HARDIN, G. The Tragedy of the Commons. Science, New York, vol. 162, December 1968.

HEIDEGGER, Martin. Ser e Tempo, edição bilíngue. 
São Paulo/Petrópolis: UNICAMP/Vozes, 2012.

: Os Conceitos Fundamentais da Metafisica: mundo, finitude, solidão. Rio de Janeiro: Forense Universitária, 2003.

: Die Armut. Heidegger Studies, Berlin vol.10, 1994, p. 5-14.

: Über den Humanismus, Frankfurt am Main: Klostermann, 1956.

: Sobre o 'humanismo'. In: Heidegger (Coleção Os Pensadores). São Paulo: Abril, 1973.

: A questão da técnica. In: Ensaios e Conferências. Petrópolis: Vozes, 2002.

: Serenidade. Lisboa: Piaget, 2000.

McLUHAN, T.C. Touch the Earth. New York: Outerbridge \& Diesntfrey, 1971.

MEADOWS, D. et all. Limits to Growth. New York: Universe Books, 1972.

NAESS, A. The Shallow and the Deep, Long Range Ecology Movement: a summary. Inquiry 16, 1973, p. 95-100.

NASH, Roderick: Wilderness and the American Mind. New Heaven: Yale University, 1967.

: The Rights of Nature. Madison: University of Wisconsin Press, 1989.

: Do Rocks have Rights? The Center Magazine, Santa Barbara, 10, 1977:2.

NOBRE, M. e AMAZONAS, M. C. Desenvolvimento Sustentável: a institucionalização de um conceito. São Paulo: Edições IBAMA, 2002.

ONU: Declaração de Estocolmo sobre o Ambiente Humano, Estocolmo, 1972. In: http://www.onu.org.br/ rio20/img/2012/01/estocolmo1972.pdf
: Convenção-Quadro das Nações Unidas sobre Mundança do Clima, Rio de Janeiro, 1992. In: http:// www.onu-brasil.org.br/doc_clima1.php

: Protocolo de Quioto à Convenção-Quadro das Nações Unidas sobre Mudança do Clima, Quioto, 1997. In: http://www.onu-brasil.org.br/doc_quioto2.php

: O Futuro que Queremos, Rio de Janeiro, 2012. In: http://www.rets.org.br/sites/default/files/O-Futuroque-queremos1.pdf

PALMER, J. 50 Grandes Ambientalistas. São Paulo: Editora Contexto, 2006.

SCHARFF, R. and DUSEK, V. Philosophy of Technology: the technological condition, $3^{\mathrm{a}}$ edição. Malden: Blackwell, 2008. 